\title{
DESIGN AND DEVELOPMENT OF A SUSTAINABILITY TOOLKIT FOR SIMULATION
}

\author{
Xi Zhou \\ Michael E. Kuhl \\ Rochester Institute of Technology \\ 81 Lomb Memorial Drive \\ Rochester, NY 14623, U.S.A.
}

\begin{abstract}
As sustainability related issues are becoming increasingly import in business decision making, simulation modeling is needed to analyze the system performance not only using traditional performance measures such as productivity and efficiency, but also taking into account sustainability related performance measures. This paper describes the design and development of a sustainability toolkit for simulation with the intent of making sustainability related performance measures as easy to model and collect as traditional productivity based performance measures. The focus here is on the development of a toolkit for modeling and analysis of environmental performance measures in discrete-event systems simulation.
\end{abstract}

\section{INTRODUCTION}

Sustainability related issues, such as energy consumption, emissions and overall environmental impact, have become increasingly important factors in business decisions. However, traditional decision support tools such as simulation have primarily focused on the operational aspects of industrial and service systems such as efficiency, productivity, and cost with little attention given to environmental impact. To address this issue, we have undertaken an effort to develop a sustainability toolkit for simulation. We plan to supplement the traditional constructs and performance measures that are provided in current simulation packages with a sustainability toolkit that will contain a flexible framework to enable the modeling and analysis of sustainability-related factors and performance measures. This toolkit is intended to be designed for ease of implementation, so decision-makers can have sustainability measures as readily available as traditional performance measures when making decisions.

Sustainability is often seen as having three major aspects or components - a social aspect, an economic aspect, and an environmental aspect - which are interdependent (see Figure 1). The long term plan for the sustainability simulation toolkit is to provide a toolset that takes an integrative systems approach to modeling and analyzing problems including all three aspects of sustainability. This paper discusses the initial design and development of the sustainability toolkit which focuses on the environmental aspect of sustainability.

This paper builds on Kuhl and Zhou (2009) where the concept of a sustainability simulation toolkit was first introduced. In particular, we outline our methodology for the design and development of the environmental aspects of the toolkit. The environmental aspect of sustainability may use ecosystemoriented, product-oriented, or process-oriented analysis methods. Here, we utilize process-oriented analysis methods. We illustrate the current status of the toolkit and its implementation including modules that have been developed for modeling and collecting environmental performance measures for transportation and logistics systems, industrial processes, and material handling systems. We demonstrate the implemen- 


\section{Zhou and Kuhl}

tation of the current toolkit using the ARENA simulation software package and provide examples utilizing the toolkit modules.

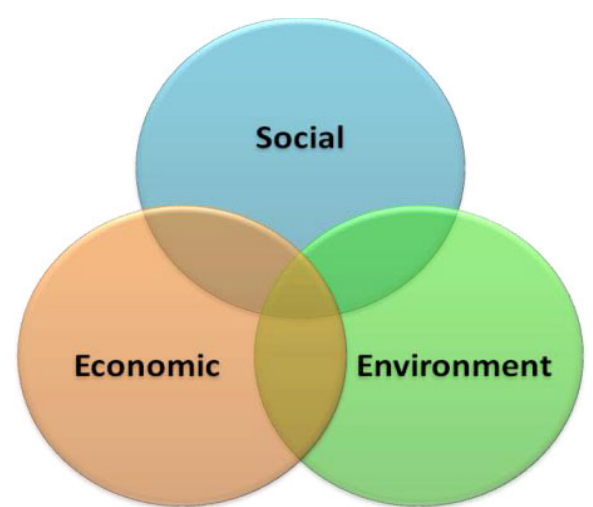

Figure 1: Three major aspects of sustainability - social, economic, and environment

\section{METHODOLOGY FOR THE DEVELOPMENT OF SUSTAINABILTY TOOLKIT MODULES}

The general methodology for developing the process-oriented, environmental modules of the sustainability simulation toolkit involves the following steps:

- Identify sustainability factors and environmental performance measures for systems of interest;

- Establish simulation state variables to represent the sustainability factors and performance measures;

- Identify the events in the system that cause changes to the state variables, and translate these system events to simulation events and the associated event triggers;

- Establish the mathematical, statistical, and logical relationships among the state variables to update and change the values of the state variables as events occur in the system over time;

- Implement state variables, relationships, and events into a robust, flexible simulation toolkit modules; and

- Perform verification, validation, and testing of the simulation toolkit modules.

Since we are utilizing discrete-event simulation, the changes to the state-variables will occur upon the instantaneous occurrence of events. For items such as emissions which may occur continuously over an interval of time, we will assume (at least initially) that emission quantity between event occurrences can be represented as a function of time, a probability distribution, or a stochastic process. In the future, it may be necessary to represent some factors as continuous variables with respect to time and utilize difference and/or differential equations to accurately represent some systems. Upon determining the mathematical, statistical, and logical relationships among state-variables, they are implemented into the sustainability toolkit consisting of a flexible framework of modules which are developed for integration into off-theshelf and customized simulation software. Initially, this will take the form of implementing the modules in the ARENA simulation software. Upon gaining these capabilities our intention is to implement the modules in a general programming language such as $\mathrm{C}++$ and provide "hooks" on the toolkit modules that will allow for easy adaptation to off-the-shelf simulation languages.

\section{CURRENT DEVELOPMENT AND IMPLEMENTATION OF TOOLKIT MODULES}

The development of the sustainability toolkit has resulted in the implementation of modules for modeling and analysis of three important and commonly encountered system components including transportation and logistics, industrial processes, and material handling. Figure 2 depicts the ARENA template that has been created using the template development tools provided in ARENA. The modules created in this tem- 


\section{Zhou and Kuhl}

plate can be used in conjunction with the other templates and modules provided with ARENA. In the following sections, we describe the development and functionality of the modules and provide examples to illustrate their use.

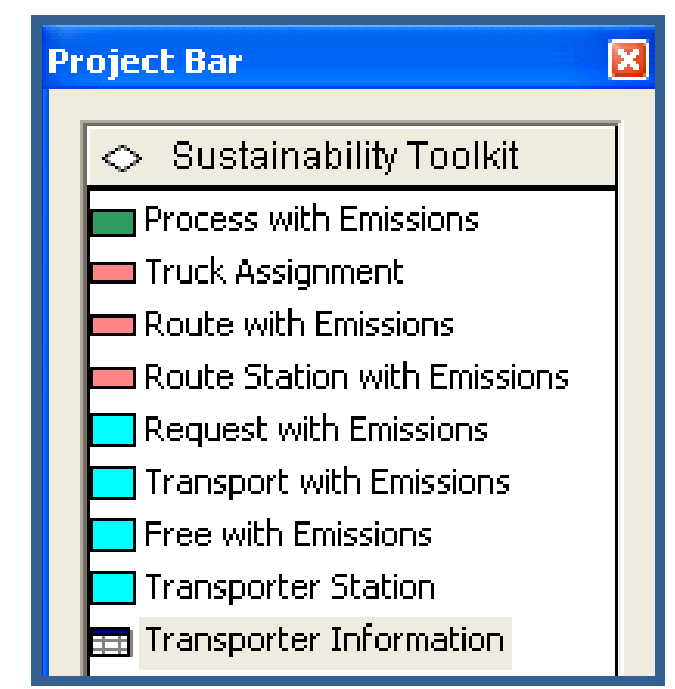

Figure 2: Current sustainability toolkit implementation

\subsection{Transportation and Logistics Modules}

In Kuhl and Zhou (2009), the concept of modules for modeling transportation and logistics systems is introduced. Since then, more flexible versions of the modules have been developed and are summarized here. For additional details, please refer to Kuhl and Zhou (2009). The revised transportation toolkit consists of three modules including the Truck Assignment module, Station with Emissions module, and Route with Emissions module (see Figure 2).

In the transportation and logistics systems, we assume that the vehicle (truck) will be represented as an entity that flows through the simulation model logic and travels among locations (stations). Therefore, a user can create an entity (using a traditional Create module) and then have the entity enter the Truck Assignment module to define and assign the attributes of a Truck to the entity and set up the desired statistics collection options.

Figure 3 depicts the dialog boxes for the Truck Assignment module. Based on the vehicle type that is specified (e.g. Truck, Van, SUV), a second dialogue is opened for more detailed information about the vehicle. Taking the truck as an example, the user is asked to provide the information for the trucks, which includes the truck engine horsepower, the truck efficiency (measured in miles per gallon), the average speed of the truck and the fuel capacity. The user chooses the fuel type for the trucks to use. There are five types of fuel provided by our model, including the diesel, 10\% soya blend biodiesel (B10), 20\% soya blend biodiesel (B20), 30\% soya blend biodiesel (B30) and 40\% soya blend biodiesel (B40). Among four available emissions $\left(\mathrm{CO}, \mathrm{CO}_{2}, \mathrm{NO}_{\mathrm{x}}, \mathrm{THC}\right)$, the user may select which emission components they are interested in collecting. The default mathematical relationship to calculate the emissions have been adapted from Manicom et al. (1993) as

$$
f_{Y}(t)=C_{Y, Z} h t=\frac{C_{Y, Z} h d}{s}
$$

where the emissions produced $f$ of emission component $Y$ over time interval $t$ is equal to the emission coefficient $C_{Y, Z}$ for emission component $Y$ given fuel type $Z$ times the truck horsepower $h$ times the time period length. Furthermore, the time interval $t$ can be calculated based on the distance $d$ and the average 


\section{Zhou and Kuhl}

speed $s$. Manicom et al. (1993) provide a list of $C_{Y, Z}$ which are used as the default value in the toolkit. The user has the control of changing the emission coefficient based on other studies that exist or may become available in the future.

The Route Station with Emissions module (see dialogue box in Figure 4a) provides the same functionality (representing a physical location) as a Station module in the ARENA. Additionally, when trucks arrive at a customer, which is modeled as a Station, our Route Station with Emissions module collects the emissions generated along the route from the previous location. The module accumulates the system emissions as well. Finally, the user can specify the probability of the truck idling while it remains at the station location.

The Route with Emissions module (see dialogue box in Figure $4 \mathrm{~b}$ ) provides the functionality of the Route module in ARENA and also calculates accumulating emissions while the truck remains at the station. It is used to route the truck to the next customer after the truck leaves the current location. The module provides two options to the user for entering the route information. The user can provide the route distance or the route time. The system cumulative emissions are updated in this module as well.
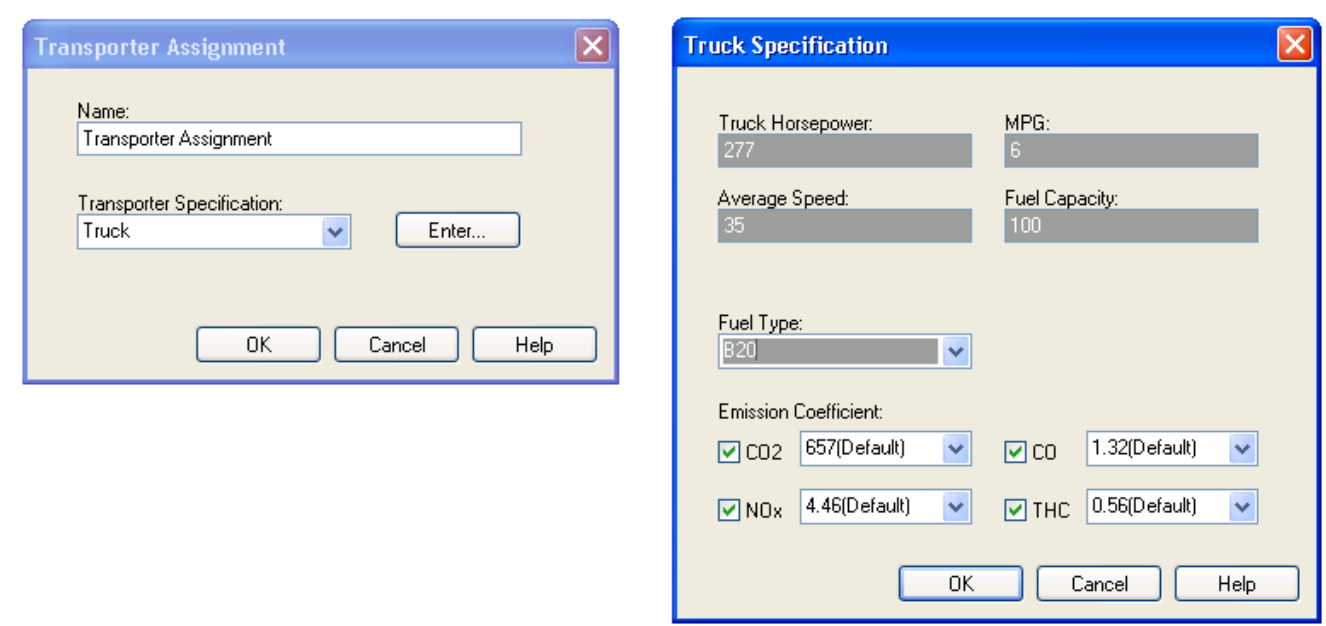

Figure 3: Simulation Module Dialogue Boxes: Truck Assignment Module

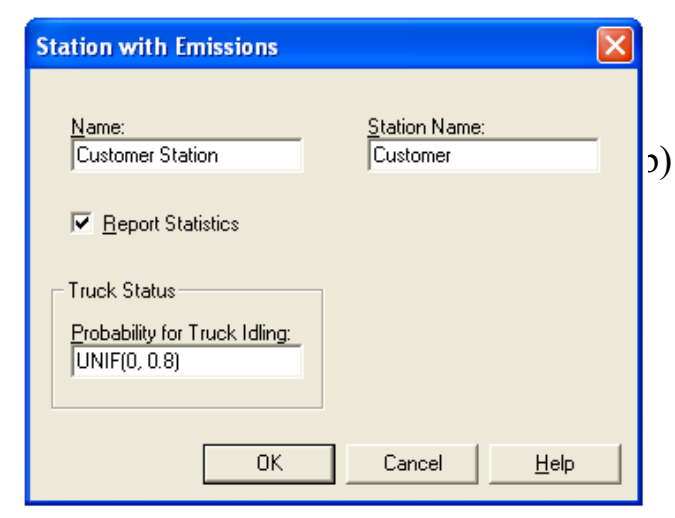

(a)

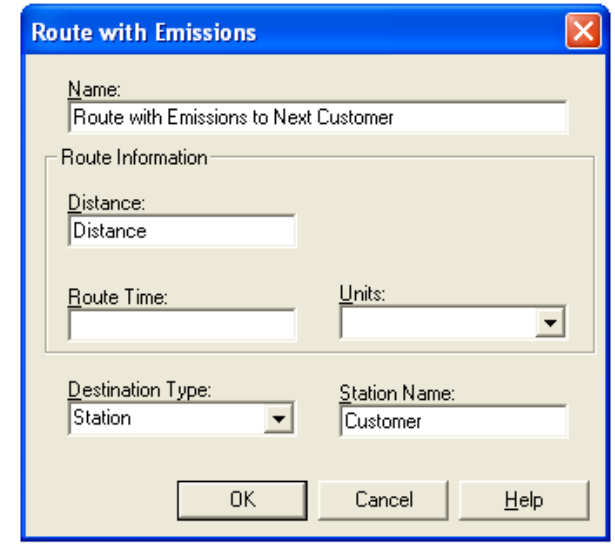

(b)

Figure 4: Simulation Module Dialog Boxes: (a) Station with Emissions, (b) Route with Emissions

Example 1 Suppose a company has a centralized warehouse facility from which it makes deliveries to customers on a daily basis. The company currently has 8 trucks that consume diesel fuel. Each day 
routes are assigned to trucks. The route may consist of a variable number of delivery stops at customers and variable route distances that can each be represented by a probability distribution. The company needs to replace part of its fleet of trucks. The company wants to determine the number and type of trucks to purchase (e.g. capacity, type of fuel, and engine power) while taking into account the energy consumption and emissions in addition to traditional system performance measures such as cost and customer service level. Detailed specifications are provided in Table 1. Figure 5 represents a random instance of truck routings of deliveries to customers and returning to the warehouse.

Table 1: Simulation Parameter Specifications

\begin{tabular}{ll}
\hline Specification & Assigned Value \\
\hline Number of Trucks & 8 Trucks \\
Truck Horsepower & 277 Horsepower \\
Truck Fuel Economy & 6 Miles per Gallon \\
Truck Average Speed & 35 Miles per Hour \\
Truck Fuel Capacity & 100 Gallons \\
Fuel Type & $20 \%$ Soya Blend Biodiesel \\
Route Distance & $22+275 \times$ BETA $(0.896,2.77)$ Miles \\
Number of Customers & Random Integer between 1 and 10 \\
Probability for Truck Idling & Random Number between 0 and 1 \\
Number of Product Boxes Unloaded & Random Integer between 1 and 10 \\
Unloading Time & 2 Minutes per Box \\
\hline
\end{tabular}

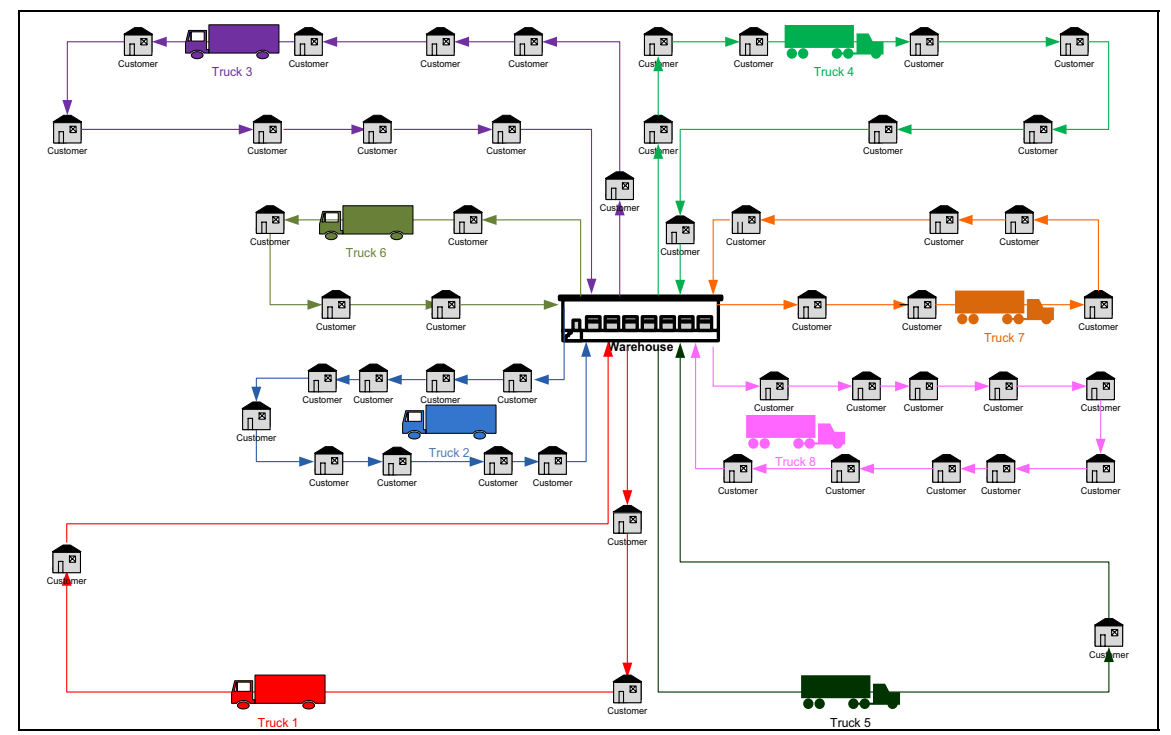

Figure 5: Diagram of a Sample Instance of Truck Routings Generated via the Example Simulation Model

The simulation model constructed for Example 1 is shown in Figure 6. Given the toolkit modules, we utilize them along with standard ARENA modules to represent the transportation system. Entities representing the 8 trucks are created in the Create module. The Truck Assignment module is used to assign truck parameters as well as to specify the emissions to collect. The routings for this example are specified in the traditional assign modules. The first Route with Emissions module (labeled Route with Emissions to Customer) is used to specify the routing of the truck from the warehouse to the first customer. The Route Station with Emission module (labeled Customer Station) represents the location of a "generic" customer. At each customer location, a Process module is used to represent the delivery process. The Decide module is used to determine if the route has been complete. If so, the Route with Emissions module 


\section{Zhou and Kuhl}

(labeled Route with Emissions to Warehouse) is used to route the truck back to the warehouse. If the route is not complete, the Route with Emissions module (labeled Route with Emissions to Next Customer) is used to send the truck to the next customer on the route. The simulation model is set up to represent a simulation length of a 5 day week.

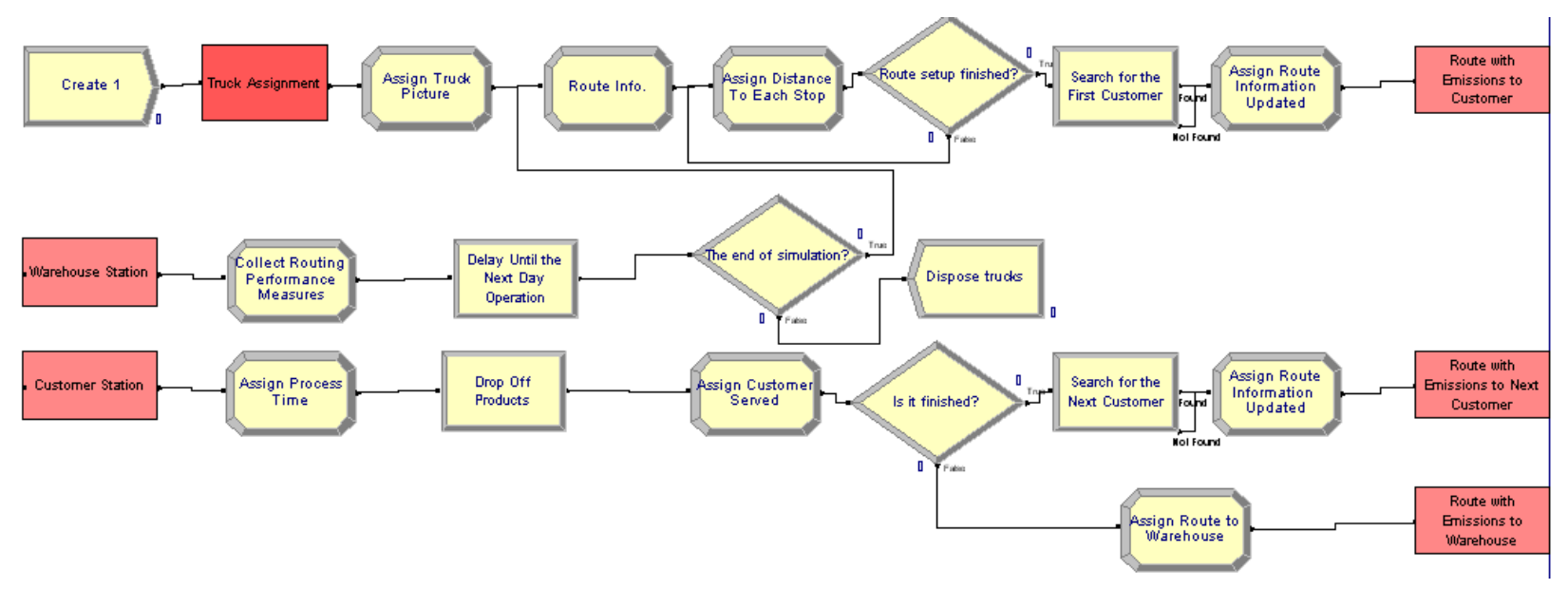

Figure 6: Example 1, Transportation Simulation Model

To demonstrate the use of the simulation model, the model was set up and run. Table 2 shows the output of the simulation model including both the environmental performance measures and the traditional system performance measures for the model run for one replication of 5 days using 8 trucks utilizing $20 \%$ soya blend biodiesel. The performance measures are collected and shown for each truck and for the entire system.

Table 2: Example of Simulation Results for Trucks using 20\% Soya Blend Biodiesel over 5 Days

\begin{tabular}{lrrrrrrrrr}
\hline & Truck 1 & Truck 2 & Truck 3 & Truck 4 & Truck 5 & Truck 6 & Truck 7 & Truck 8 & System \\
\hline CO Emissions (g) & $8,276.2$ & $2,650.5$ & $5,442.2$ & $5,021.6$ & $4,728.0$ & $5,877.8$ & $5,724.4$ & $6,286.3$ & $44,007.0$ \\
$\mathrm{CO}_{2}$ Emissions (g) & $4.1 \mathrm{E}+6$ & $1.3 \mathrm{E}+6$ & $2.7 \mathrm{E}+6$ & $2.5 \mathrm{E}+6$ & $2.4 \mathrm{E}+6$ & $2.9 \mathrm{E}+6$ & $2.8 \mathrm{E}+6$ & $3.1 \mathrm{E}+6$ & $2.2 \mathrm{E}+7$ \\
$\mathrm{NO}_{\mathbf{x}}$ Emissions (g) & $2.8 \mathrm{E}+4$ & $9.0 \mathrm{E}+3$ & $1.8 \mathrm{E}+4$ & $1.7 \mathrm{E}+4$ & $1.6 \mathrm{E}+4$ & $2.0 \mathrm{E}+4$ & $1.9 \mathrm{E}+4$ & $2.1 \mathrm{E}+4$ & $1.5 \mathrm{E}+5$ \\
THC Emissions (g) & $3,511.1$ & $1,124.4$ & $2,308.8$ & $2,130.3$ & $2,005.8$ & $2,493.6$ & $2,428.5$ & $2,666.9$ & $18,669.0$ \\
Route Distance (mi.) & 703.6 & 198.9 & 401.9 & 381.5 & 384.9 & 492.6 & 482.6 & 532.9 & $3,579.0$ \\
$\begin{array}{l}\text { Route Time (hrs.) } \\
\text { Fuel }\end{array}$ & 25.2 & 8.8 & 17.1 & 17.8 & 14.5 & 18.6 & 19.1 & 19.7 & 140.9 \\
$\begin{array}{l}\text { Consumed (gal.) } \\
\begin{array}{l}\text { Customers } \\
\text { Served }\end{array}\end{array}$ & 117.3 & 33.1 & 67.0 & 63.6 & 64.2 & 82.1 & 80.4 & 88.8 & 596.5 \\
\hline & 28.0 & 18.0 & 34.0 & 40.0 & 18.0 & 24.0 & 29.0 & 30.0 & 221.0 \\
\hline
\end{tabular}

\subsection{Process with Emissions Module}

Industrial processes, such as chemical manufacturing, coating processes, and cement manufacturing, involve energy and material consumption and generate environmental emissions. We introduce a Process with Emission module in the sustainability toolkit which provides the user with a flexible framework to model industrial processes. Here our effort is to design and develop a flexible framework where predefined processes and statistics can be easily utilized while the user is also allowed to collect additional statistics and define additional processes along with their process characteristics.

The Process with Emission module dialog box is shown in Figure 7. The upper portion of the dialog box provides the functions of a traditional process module. In the lower portion, additional functionality is provided for process specifications. The dialog box changes dynamically depending on the process type 


\section{Zhou and Kuhl}

selected. Currently, there is one predefined process which is an industrial coating process. Other predefined processes will be added as the toolkit is developed. The dialog box where the user specifies the coating process parameters is shown in Figure $7 \mathrm{~b}$. If a user-defined process is selected or additional statistics are desired, corresponding dialog boxes are provided for user input.

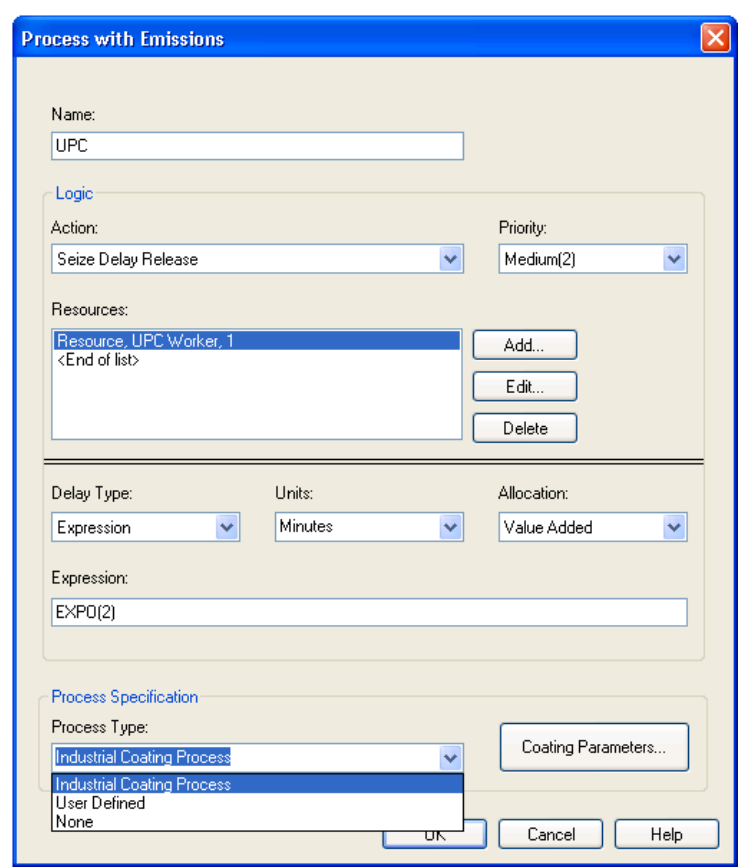

(a)

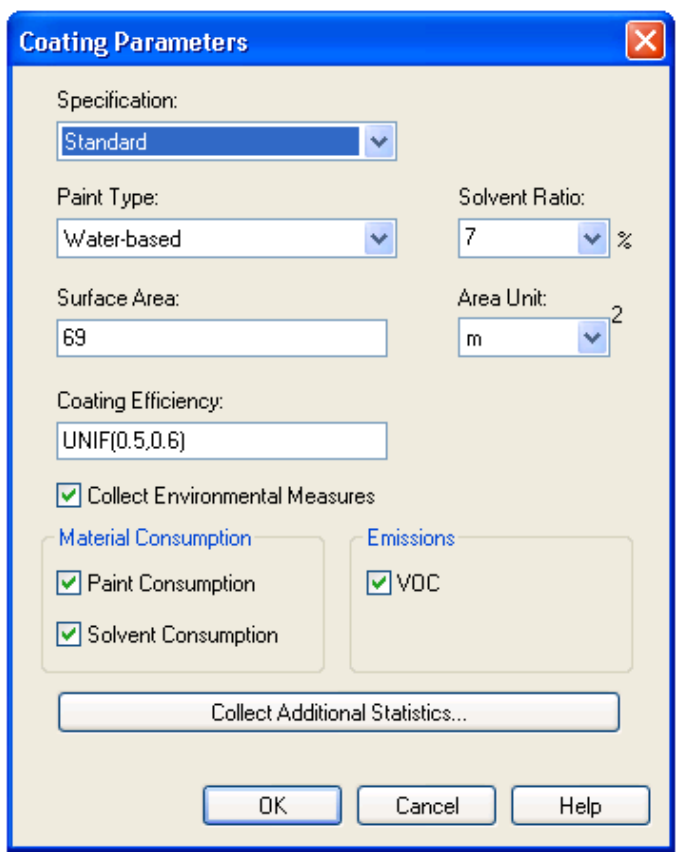

(b)

Figure 7: (a) Process with Emission Dialog Box; and (b) Coating Parameters Dialog Box

The predefined industrial coating process is based on a study by Rentz et al. (2002) involving various industrial coating process applied to vehicles. The quantity of paint consumed to coat the vehicles is a function of several parameters including the coating area, the paint usage coefficient, and the coating process efficiency. Rentz et al. (2002) provide a list of the paint usage coefficient for various coating material including water-based paint and solvent-based paint. The paint usage coefficient is in the units of grams per square meter (grams $/ \mathrm{m}^{2}$ ). The equation for calculating the paint consumption is:

$$
f_{j}(x, Z)=\frac{C(Z) A(x)}{e f f}
$$

where the paint consumed $f$ by using paint type $Z$ to paint vehicle $x$ in process $j$ is equal to the paint usage coefficient $C(Z)$ for paint type $Z$ times the painting area $A(x)$ for vehicle $x$ divided by the painting process efficiency eff. The solvent consumption is calculated as:

$$
g_{j}(x, Z)=r(Z) f(x, Z)
$$

where the solvent consumed $g$ by using paint type $z$ to paint vehicle $x$ in process $j$ equal to the paint consumption $f$ times the solvent ratio of paint type $Z$. Rentz et al. (2002) study the emissions generated from coating the vehicle as well. The results of the research study provide that the volatile organic compounds (VOC) generated $V$ by using paint type $Z$ to paint vehicle $x$ in process $j$ is calculated as the VOC emission coefficient of paint type $Z$ times the painting area $A(x)$ for vehicle $x$ divided by the painting process efficiency eff resulting in the following relationship:

$$
V_{j}(x, Z)=\frac{\tau(Z) A(x)}{e f f} .
$$




\section{Zhou and Kuhl}

As a simulation model consists of processes, traditional system performance measures include the average process resource utilization, average process time, and average waiting time. Typically, the sustainability performance measures including the material consumption and emissions generation are collected for each process (e.g. VOC generation in process $j$ in total). The system performance measures are accumulated for the whole system as well (e.g. VOC generation in the system).

To illustrate the use of the Process with Emissions module, the following example is presented.

Example 2 A plant has a top coating line for coating vehicles. The top coating process consists of five sequential steps including underbody protection coating, filler application, base coat application, clear coat application and cavity sealing. In each of the five coating processes, the company can choose from solvent-based paint or water-based paint as the coating material. The company wants to evaluate this coating line on its productivity and efficiency, while taking into account the material consumption and the emissions generation, especially the generation of Volatile Organic Compounds (VOC). Table 3 contains additional details of the system.

Table 3: Material Used for Coating Processes

\begin{tabular}{|c|c|c|c|c|c|c|}
\hline & $\begin{array}{c}\text { Underbody } \\
\text { Protection } \\
\text { using filler }\end{array}$ & $\begin{array}{c}\text { Underbody } \\
\text { Protection } \\
\text { using PVC }\end{array}$ & $\begin{array}{c}\text { Filler } \\
\text { Application }\end{array}$ & Base Coating & $\begin{array}{c}\text { Clear } \\
\text { Coating }\end{array}$ & $\begin{array}{c}\text { Cavity } \\
\text { Sealing }\end{array}$ \\
\hline Paint Type & Water-based & PVC & Water-based & Water-based & $\begin{array}{c}\text { Solvent- } \\
\text { based }\end{array}$ & Powder \\
\hline Solvent Ratio & $7 \%$ & - & $7 \%$ & UNIF $(10 \%, 20 \%)$ & $40 \%$ & - \\
\hline
\end{tabular}

In this example, the predefined industrial coating process can be used to model the Underbody Protection using filler, the Filler Application, and the Clear Coating processes where paint and solvent consumption are measured along with VOCs. The Base Coating process can also be modeled as the predefined industrial coating process, but in addition requires statistics collection on $\mathrm{CO}, \mathrm{NOx}$, and dust emissions. The PVC and Cavity Sealing processes cannot be modeled as the predefined industrial coating process, but can be modeled as user-defined processes. Figure 8 shows the simulation logic applied for this example including the use of the Process with Emissions modules.

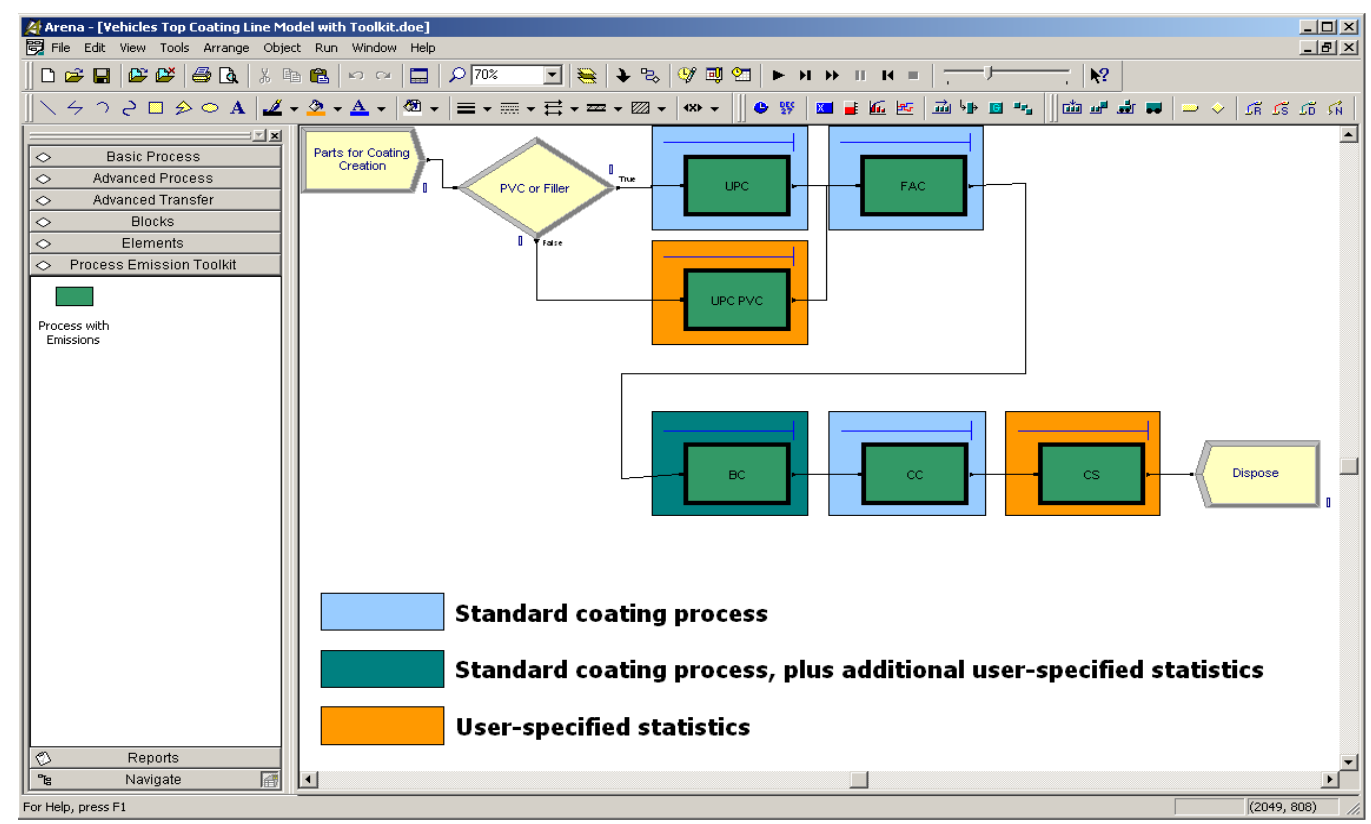

Figure 8: Example Simulation Model with Emissions Template (left side) Implemented in ARENA 


\section{Zhou and Kuhl}

To demonstrate the use of the simulation model, the model was set up and run. Table 4 shows the output of the simulation model run for one replication over 20 hours. The sustainability performance measures are collected and shown for each process and for the entire system.

Table 4: Simulation Results for Vehicles Top Coating Line over 20 hours

\begin{tabular}{|c|c|c|c|c|c|c|c|}
\hline & $\begin{array}{l}\text { Underbody } \\
\text { Protection } \\
\text { using filler }\end{array}$ & $\begin{array}{l}\text { Underbody } \\
\text { Protection } \\
\text { using PVC }\end{array}$ & $\begin{array}{l}\text { Filler Ap- } \\
\text { plication }\end{array}$ & $\begin{array}{l}\text { Base Coat- } \\
\text { ing }\end{array}$ & $\begin{array}{c}\text { Clear } \\
\text { Coating }\end{array}$ & $\begin{array}{l}\text { Cavity } \\
\text { Sealing }\end{array}$ & System \\
\hline \multicolumn{8}{|c|}{ Consumption } \\
\hline $\begin{array}{l}\text { Paint Con- } \\
\text { sumption }(\mathrm{g})\end{array}$ & $2.1 \mathrm{E}+05$ & - & $2.3 \mathrm{E}+06$ & $2.3 \mathrm{E}+06$ & $1.3 \mathrm{E}+06$ & - & - \\
\hline $\begin{array}{l}\text { Solvent Con- } \\
\text { sumption (g) }\end{array}$ & $1.5 \mathrm{E}+04$ & - & $1.6 \mathrm{E}+05$ & $3.6 \mathrm{E}+05$ & $5.2 \mathrm{E}+05$ & - & - \\
\hline $\begin{array}{l}\text { Add. PVC } \\
\text { Usage (g) }\end{array}$ & - & $3.5 \mathrm{E}+03$ & - & - & - & - & - \\
\hline $\begin{array}{l}\text { Add. Powder } \\
\text { Usage }(\mathrm{g})\end{array}$ & - & - & - & - & - & $5.5 \mathrm{E}+03$ & - \\
\hline \multicolumn{8}{|c|}{ Emissions } \\
\hline $\begin{array}{l}\text { VOC Genera- } \\
\text { tion }(\mathrm{g})\end{array}$ & $8.1 \mathrm{E}+04$ & - & $8.9 \mathrm{E}+05$ & $8.9 \mathrm{E}+05$ & $2.6 \mathrm{E}+06$ & - & $4.5 \mathrm{E}+06$ \\
\hline $\begin{array}{l}\text { Add. CO Gen- } \\
\text { eration }(\mathrm{g})\end{array}$ & - & - & - & $4.8 \mathrm{E}+03$ & - & - & $4.8 \mathrm{E}+03$ \\
\hline $\begin{array}{c}\text { Add. NOx } \\
\text { Generation }(\mathrm{g})\end{array}$ & - & - & - & $1.8 \mathrm{E}+04$ & - & - & $1.8 \mathrm{E}+04$ \\
\hline $\begin{array}{c}\text { Add. Dust } \\
\text { Generation }(\mathrm{g})\end{array}$ & - & - & - & $2.3 \mathrm{E}+03$ & - & - & $2.3 \mathrm{E}+03$ \\
\hline
\end{tabular}

\subsection{Material Handling Modules}

The transporter toolkit is designed to capture the main sources of emissions in warehouses which are emitted by material handling equipment. Important performance measures related to the emission level are collected and reported by the transporter toolkit modules as well as the traditional performance measures such as the equipment utilization, average travelling time, etc.

The Environmental Protection Agency (EPA) estimates that forklift operations generated 297,973 tons of NOx, 64,892 tons of THC, and 1,357,677 tons of CO in 2007, which shows that the forklifts are large contributors to non-road emissions. To calculate the quantity of emissions generated by operating the forklift, a formulation provided by the EPA is used. EPA provides a list of emission coefficients in the unit of grams per horsepower per hour (grams/hp $h r$ ) for various emission types. The formulation will be used to estimate emission levels of forklift equipment. Thus, we have the relationship:

$$
f_{Y}(t)=C_{Y} h t \tau=\frac{C_{Y} h d \tau}{s}
$$

where the emissions produced $f$ of emission component $Y$ over time interval $t$ is equal to the emission coefficient $C_{Y}$ for emission component $Y$ times the forklift horsepower $h$ times the time period length times the load factor $\tau$. The load factor represents the proportion of rated power used by the forklift for each of the operations executed. It is a number between 0 and 1 . This relationship can be used directly when the forklift is idling, however when the forklift is traveling between locations, the time component can be calculated as the distance traveled $d$ divided by the average speed $s$.

Based the events identified, four modules and one data module have been created. These modules include the Request with Emissions module, the Transport with Emissions module, the Free with Emissions module the Transporter Station module, and the Transporter Information data module (see Figure 9).

The Request with Emissions module has the full functionality of the traditional Request module. In addition to the parameters to be entered by the user, such as the transporter name, selection rule, and ve- 


\section{Zhou and Kuhl}

locity, the module asks the user to provide an idling probability that determines the status of the forklift when it arrives at the entity's location. The module allocates the forklift to be used and calculates the emissions generated along the route from its original location to the location where the entity requests it.

The Transport with Emissions module has the full functionality of the traditional Transport module. The user is asked to specify the station to which the entity is transported. The user also needs to specify the load factor for that movement from the current location to the destination location. The Transport with Emissions module can calculate the emissions generated during the period of time after the forklift arrives at the location if the forklift is left idling.

The Transporter Station module provides the same functionality (representing a physical location) as a Station module. Additionally, when the forklift arrives at the entity's destination, which is modeled as a Station, our Transporter Station module collects the emissions generated along the route from the location of the previous location where the entity is transported from. Finally, the user can specify the probability of the truck idling while it remains at the station location.

The Free with Emissions module frees the Forklift that is transporting the entity. It collects the emissions generated if the forklift is left idling while it remains at the station.

The Transporter Information data module asks the user to specify the necessary parameters needed in order to make the calculation for environmental performance measures. For a forklift, it asks the user to enter the rated horsepower and the load factor.

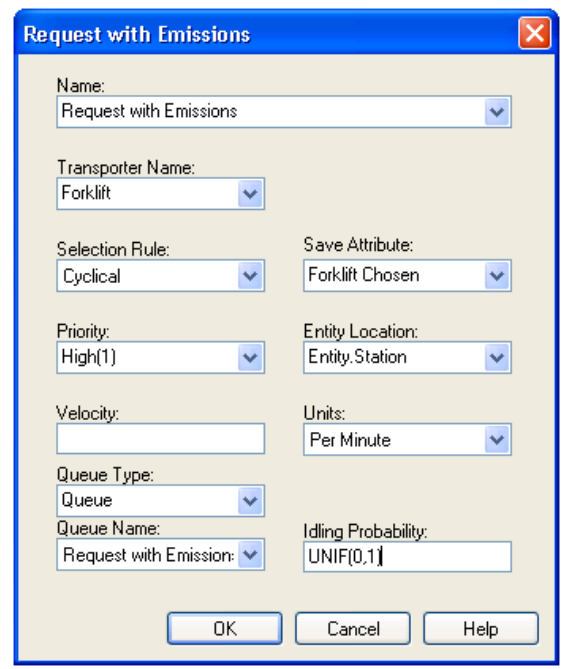

(a)

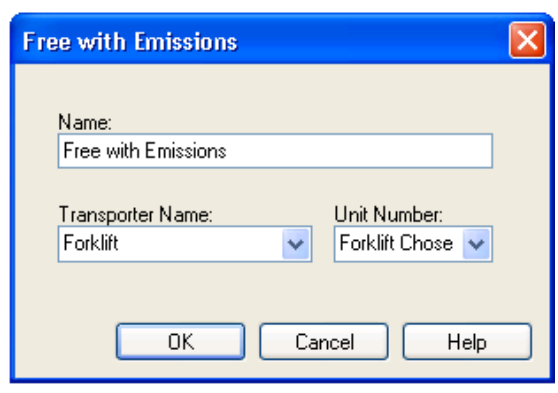

(d)

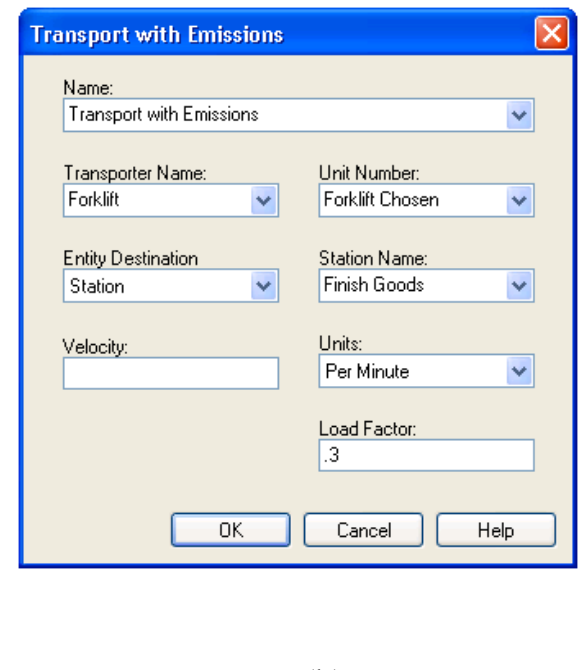

(b)

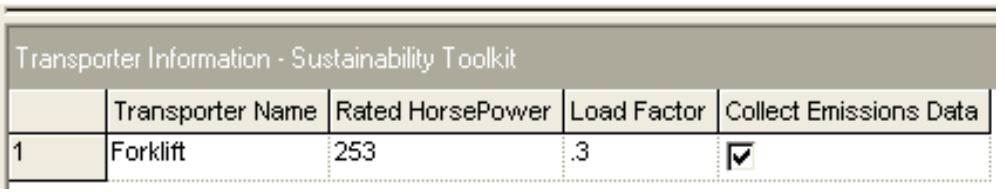

(e)

Figure 9: Transporter with Emissions Module Dialogue Boxes: (a) Request with Emissions Module, (b) Transport with Emissions Module, (c) Transporter Station, (d) Free with Emissions Module, and (e) Transporter Information. 


\section{Zhou and Kuhl}

A prototype test example of using the transporter toolkit has been created and modeled in Arena.

Example 3 Suppose a small company wants to evaluate the environmental impacts of their cross docking warehouse. A single forklift is used to transport the items among three stations which are the receiving station, intermediate station and the shipping station. Table 5 shows the parameters and specifications used in the simulation model.

\begin{tabular}{lc} 
Table 5: Simulation Parameters for Transporter Model \\
\hline Specification & Value \\
\hline Number of Forklifts & 1 \\
Forklift Rated Horsepower & 288 \\
CO Emission Factor $(\mathrm{g} / \mathrm{hp}-\mathrm{hr})$ & 285 \\
$\mathrm{CO}_{2}$ Emission Factor $(\mathrm{g} / \mathrm{hp}-\mathrm{hr})$ & 50.3 \\
$\mathrm{THC}$ Emission Factor $(\mathrm{g} / \mathrm{hp}-\mathrm{hr})$ & 126 \\
$\mathrm{NO}_{\mathrm{x}}$ Emission Factor $(\mathrm{g} / \mathrm{hp}-\mathrm{hr})$ & 83.25 \\
Load Factor & 0.3 \\
\hline
\end{tabular}

Figure 10 displays the overall simulation model using the sustainability toolkit. The model is run for 220 hours and the results from running the model are shown in Table 6.

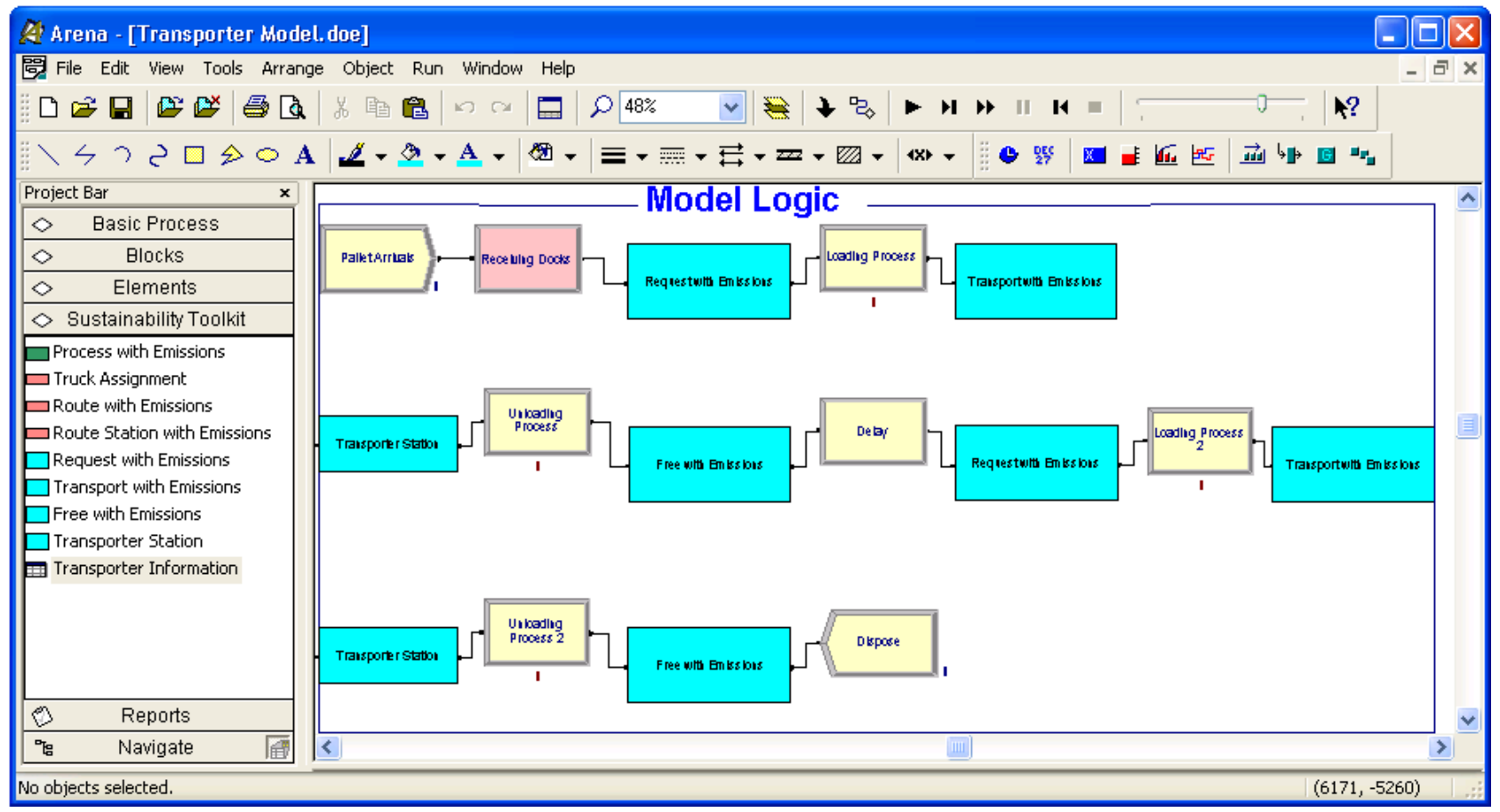

Figure 10: Example Transporter Model with Sustainability Toolkit (left side) Implemented in ARENA

Table 6: Simulation Results from running Transporter Model

\begin{tabular}{lc}
\hline $\begin{array}{l}\text { Environmental } \\
\text { Performance Measures }\end{array}$ & Value \\
\hline $\mathrm{CO}_{2}$ Emissions $(\mathrm{g})$ & $9.91 \mathrm{E}+03$ \\
$\mathrm{CO}$ Emissions $(\mathrm{g})$ & $2.74 \mathrm{E}+05$ \\
$\mathrm{THC}$ Emissions $(\mathrm{g})$ & $1.84 \mathrm{E}+05$ \\
$\mathrm{NO}_{\mathrm{x}}$ Emissions $(\mathrm{g})$ & $1.01 \mathrm{E}+05$ \\
\hline
\end{tabular}




\section{Zhou and Kuhl}

\section{CONCLUSIONS AND FUTURE WORK}

In this paper, we illustrated the current status of a sustainability simulation toolkit. We have established the methodology for developing such a toolkit and demonstrated the development of toolkit modules with application to transportations systems, industrial processes, and material handling systems. The toolkit shows a flexibility for applying it to various systems. From this prototype, we have shown the benefit that can be provided to simulation researchers and practitioners interested in including sustainability and environmental impact performance measures as an integral part of the decision making process.

It is our intention to continue the development of the sustainability simulation toolkit for a wide variety of applications and domains where sustainability plays a critical role in operational decisions. We further plan to develop a more generalized framework of the toolkit in a general programming language with compatible translator to be used by simulation software.

\section{ACKNOWLEDGMENTS}

We thank Drs. Andres Carrano, Brian Thorn, and Ruben Proano, our colleagues at Rochester Institute of Technology for their expertise, support, and collaboration on this project and its continued development.

\section{REFERENCES}

Barth, M. 1998. Integrating a modal emissions model into various transportation modeling frameworks. Paper presented at the conference on Transportation Planning and Air Quality, Emerging Strategies and Working Solutions, Lake Tahoe, CA, USA.

Kuhl, M.E., and X. Zhou. 2009. Sustainability Toolkit for Simulation-based Logistics Decisions. In Proceedings of the 2009 Winter Simulation Conference, eds. M. D. Rossetti, R. R. Hill, B. Johansson, A. Dunkin and R. G. Ingalls, 1466-1473. Piscataway, New Jersey: Institute of Electrical and Electronics Engineers.

Manicom, B., C. Green, C., and W. Goetz. 1993. Methyl Soyate Evaluation of Various Diesel Blends in a DDC 6v-92 TA Engine. Mississauga, Ontario: Ortech International.

Rentz, O., N.-H. Peters, S. Nunge, and J. Geldermann. 2002. Best Available Techniques (BAT) for the Paint - and Adhesive Application in Germany - Volume I: Paint Application. Institut FrancoAllemand de Recherche sur l'Environnement (IFARE), Universite' de Karlsruhe (Chapter 1).

U.S. Environmental Protection Agency. 2002, September. Emission Standards for New Nonroad Engines.

U.S. Environmental Protection Agency. 1991, November. Nonroad Engine and Vehicle Emission Study Report. Washington DC: Office of Air and Radiation (ANR-443).

\section{AUTHOR BIOGRAPHIES}

XI ZHOU is a graduate student pursuing a Master's degree in Industrial and Systems Engineering at Rochester Institute of Technology. His research interests are in the field of systems modeling and analysis. His e-mail address is <xi.zhou@mail.rit.edu>

MICHAEL E. KUHL is a Professor in the Industrial and Systems Engineering Department at Rochester Institute of Technology. He has a Ph.D. in Industrial Engineering from North Carolina State University (1997). His research interests include simulation modeling methodologies with application to cyber security, healthcare, and sustainability. He served as Proceedings Editor for the 2005 Winter Simulation Conference. He is a member of the INFORMS Simulation Society, IIE and ASEE. His e-mail address is $<$ Michael.Kuhlerit.edu> and his Web address is <people.rit.edu/mekeie>. 